\title{
Deep water towed array measurements at close range
}

\author{
Kevin D. Heaney, ${ }^{\text {a) }}$ Richard L. Campbell, and James J. Murray \\ Ocean Acoustical Services and Instrumentation Systems, Inc., 11006 Clara Barton Drive, Fairfax Station, \\ Virginia 22039
}

\begin{abstract}
Arthur B. Baggeroer
Departments of Ocean and Electrical Engineering and Computer Science, Massachusetts Institute of Technology, Cambridge, Massachusetts 02139
\end{abstract}

Eddie K. Scheer and Ralph A. Stephen

Woods Hole Oceanographic Institution, Woods Hole, Massachusetts 02543

Gerald L. D'Spain

University of California, San Diego, Marine Physical Laboratory La Jolla, California 92093

James A. Mercer

Applied Physics Laboratory, University of Washington, Seattle, Washington 98105

(Received 9 November 2012; revised 21 March 2013; accepted 26 March 2013)

\begin{abstract}
During the North Pacific Acoustic Laboratory Philippine Sea 2009 experiment, towed array receptions were made from a towed source as the two ships transited from a separation of several Convergence Zones through a Closest Point of Approach at $3 \mathrm{~km}$. A combination of narrowband tones and broadband pulses were transmitted covering the frequency band $79-535 \mathrm{~Hz}$. The received energy arrives from two general paths — direct path and bottom bounce. Bearing-time records of the narrowband arrivals at times show a $35^{\circ}$ spread in the angle of arrival of the bottom bounce energy. Doppler processing of the tones shows significant frequency spread of the bottom bounce energy. Two-dimensional modeling using measured bathymetry, a geoacoustic parameterization based upon the geological record, and measured sound-speed field was performed. Inclusion of the effects of seafloor roughness and surface waves shows that in-plane scattering from rough interfaces can explain much of the observed spread in the arrivals. Evidence of out-of-plane scattering does exist, however, at short ranges. The amount of out-of-plane scattering is best observed in the broadband impulsebeam response analysis, which in-plane surface roughness modeling cannot explain.
\end{abstract}

(C) 2013 Acoustical Society of America. [http://dx.doi.org/10.1121/1.4818869]

PACS number(s): 43.30.Gv, 43.30.Zk, 43.30.Dr [JAC]

Pages: $3230-3241$

\section{INTRODUCTION}

During the North Pacific Acoustic Laboratory (NPAL) Philippine Sea 2009 experiment, a wide variety of towed array measurements were made with the Office of Naval Research Five-Octave Research Array (FORA) (Becker and Preston, 2003; Becker et al., 2005). For distances within a convergence zone $(\mathrm{CZ})$ in deep water, the receiver is in the acoustic shadow zone until ranges are short enough to permit direct path propagation. This direct path range is dependent upon the gradient of the near-surface sound speed profile (SSP) and the source-receiver depths. For typical mid-ocean SSPs and $100 \mathrm{~m}$ source/receiver depths, the range to the direct-path shadow is on the order of $7 \mathrm{~km}$. The edges of the shadow will be dependent upon acoustic diffraction and seasurface scattering conditions. Within the acoustic shadow, the mechanism for propagating sound from the source to the receiver is scattering from the seafloor. This bottom bounce includes specular boundary reflections (angle-in is equal to angle-out) between the source/receiver pair, vertical scattering in the source-receiver plane, and out-of-plane scattering.

\footnotetext{
a) Author to whom correspondence should be addressed. Electronic mail: OceanSound04@yahoo.com
}

These propagation paths are evident in Fig. 1, where a measured SSP from the Philippine Sea (April 2010) is plotted, along with a parabolic equation (PE) incoherent broadband $(90-180 \mathrm{~Hz}$ ) average transmission loss (TL) for a $15 \mathrm{~m}$ source. The strong convergence zone at $63 \mathrm{~km}$ is evident as well as the direct-path energy propagating to ranges of $7 \mathrm{~km}$ for shallow receivers. Penetration of the acoustic energy into the seafloor below the source out to $30 \mathrm{~km}$ is also visible. The bathymetry along the two-dimensional (2D) radial is from a collection of multibeam bathymetry surveys taken during the experiment.

In this paper, narrowband and broadband towed array measurements from $65 \mathrm{~km}$ to the closest point of approach (CPA) of two passing ships (source/receiver) are examined. Analysis is focused on the bottom bounce energy, which is observed for all ranges. In particular, the energy is spread in angle, Doppler and arrival time. This analysis is familiar in the context of shallow water reverberation (Bucker and Morris, 1967; Cox, 1996; Desharnais and Ellis, 1997) but is less clearly understood in terms of its impact on passive single bottom bounce detection in deep water. PE modeling is used to determine which portion of the spread in arrival angle/time is due to in-plane vertical scattering from rough interfaces and how much of it is due to out-of-plane scattering. 

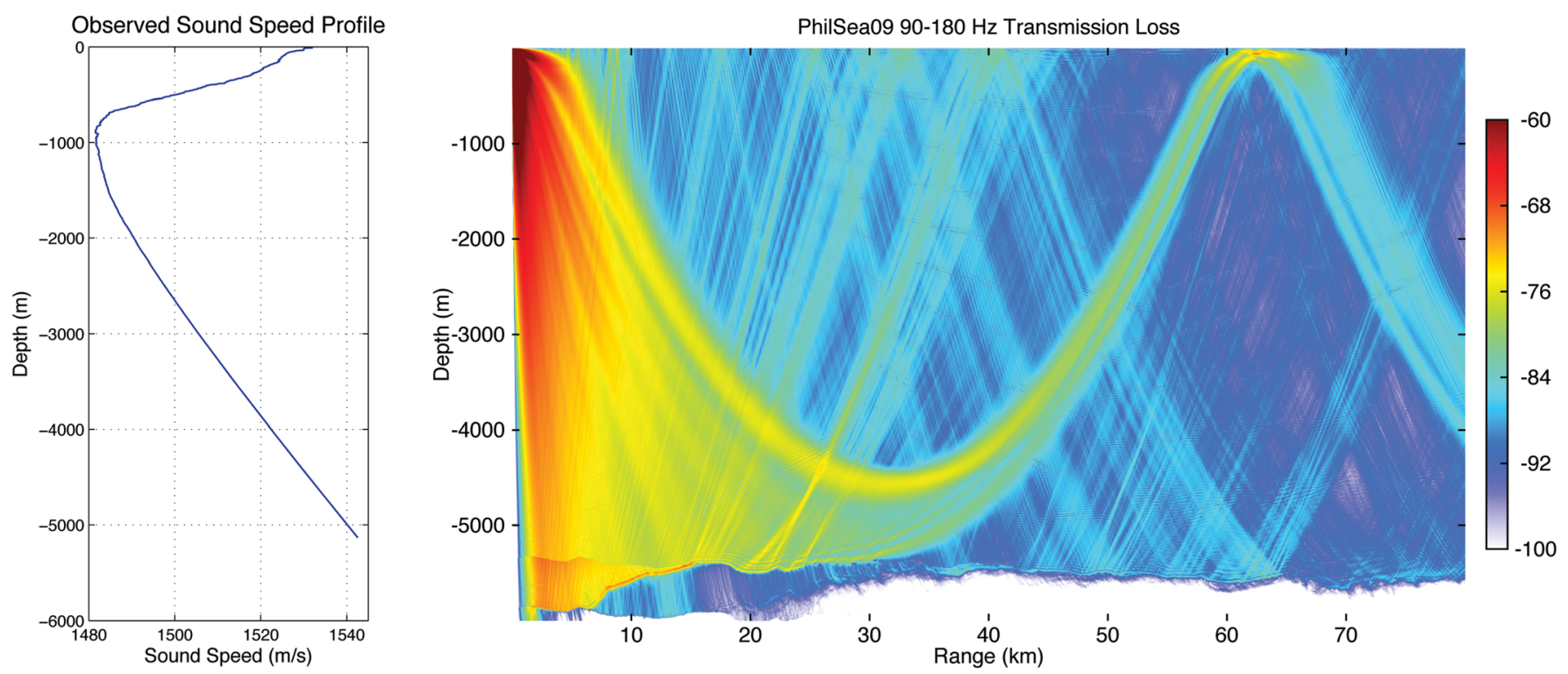

FIG. 1. (Color online) (Left) Measured profile from PhilSea09 during J15-Tow. (Right) Broadband parabolic equation transmission loss (TL) computation with measured bathymetry and surface waves. Units are dimensionless in decibels (dB).

This paper is organized as follows. In Sec. II, the experimental results are reviewed, presenting the observation of direct and seafloor interacting paths. In Sec. III, narrowband (continuous wave, $\mathrm{CW}$ ) beamforming results are presented along with Nx2D parabolic equation modeling of the experiment. Doppler analysis, including both array averaged measurements and numerical modeling, is presented in Sec. IV. Section V is the analysis of a broadband transmission at very close range. The conclusion and summary is in Sec. VI.

\section{EXPERIMENT GEOMETRY AND SIGNAL MEASUREMENTS}

During the NPAL PhilSea09 experiment the Office of Naval Research Five Octave Research Array (FORA) was deployed from the R/V Kilo Moana. The FORA array is a nested array. The ultra-low frequency aperture had an element spacing of $3 \mathrm{~m}$ and a total aperture of $196 \mathrm{~m}$ (Becker et al., 2005). Due to mechanical failure within a cable connector, only half the array was deployed for the latter half of the experiment. For the analysis in this paper, spanning the range of frequencies from 60 to $535 \mathrm{~Hz}$, the very-low frequency aperture was used with an element spacing of $1.5 \mathrm{~m}$ and a total aperture of $96 \mathrm{~m}$. The data sample rate was $8 \mathrm{kHz}$. Sources recorded on the FORA array include the T1 tomography source deployed by Scripps Institution of Oceanography, a pair of low frequency ship-suspended sources deployed by the Applied Physical Laboratory, University of Washington, and a J15-3 deployed from the R/V Melville. For shallow source/receiver combinations, an emphasis in the measurements was on ranges of 50-70 km corresponding to the first $\mathrm{CZ}$. Geometries included a linear tow out to three CZs ( 200 km), multiple CZ crossings at different azimuths, a constant range $(65 \mathrm{~km})$ arc, and two CPAs with ranges from one $\mathrm{CZ}$ to within $3 \mathrm{~km}$. In this paper, we focus on the
CPA event on 1445 UTC on JD113 in which the R/V Melville and R/V Kilo Moana passed each other at opposite headings. The ship positions, transmission distances and relative bearings during the event are shown in Fig. 2. During the closing portion of the experiment (times $<1935$ UTC), the heading of the R/V Kilo Moana alternated from $+15^{\circ}$ to $-15^{\circ}$ away from the closing heading to the R/V Melville. The R/V Kilo Moana is a relatively noisy ship, and this zigzag behavior kept the signal energy from the source off of the forward endfire beam.

The J-15 source transmitted a combination of narrowband and broadband tones to study both narrowband processes, such as detectors, and the impulse response of the channel. A large set of narrowband tones from 80-230 and $355-533 \mathrm{~Hz}$ were transmitted in $7 \mathrm{~Hz}$ steps with varying source levels. The strongest tones, examined here, were at frequencies of 79, 100, 135, 198, 355, and $405 \mathrm{~Hz}$. The CW tone set was transmitted for $230 \mathrm{~s}$. This was followed by a $5 \mathrm{~s}$ gap, a $12 \mathrm{~s} 90-180 \mathrm{~Hz}$ linear frequency modulation (LFM) sweep, a $5 \mathrm{~s}$ gap and then a $12 \mathrm{~s} 375-525 \mathrm{~Hz}$ sweep. The pulse-repetition interval for the entire sequence was $300 \mathrm{~s}$. The frequencies were chosen to stay outside of the $225-325 \mathrm{~Hz}$ band, which was the operating frequency of the moored source used for other measurements. The total source level of the J-15 was $171 \mathrm{~dB}$ re $1 \mu \mathrm{Pa}^{2} @ 1 \mathrm{~m}$. An element-averaged spectrogram from the test is shown in Fig. 3. Note the low and high frequency LFMs, which appear as doublets, due to the late arriving bottom bounce. The strong line at $300 \mathrm{~Hz}$ is from the R/V Kilo Moana.

To set up the analysis and interpretation, we present a narrowband bearing time record (BTR) for $355 \mathrm{~Hz}$ for JD 113 from 1200 UTC to 2400 UTC (Fig. 4). This includes closing from a range of $22 \mathrm{~km}$, the CPA and opening to a range of $18 \mathrm{~km}$. The CPA is at 1945 UTC and is evident from the high bearing-rate signal. A lower bearing-rate sweep from 1800 UTC to greater than 2300 UTC is clearly 

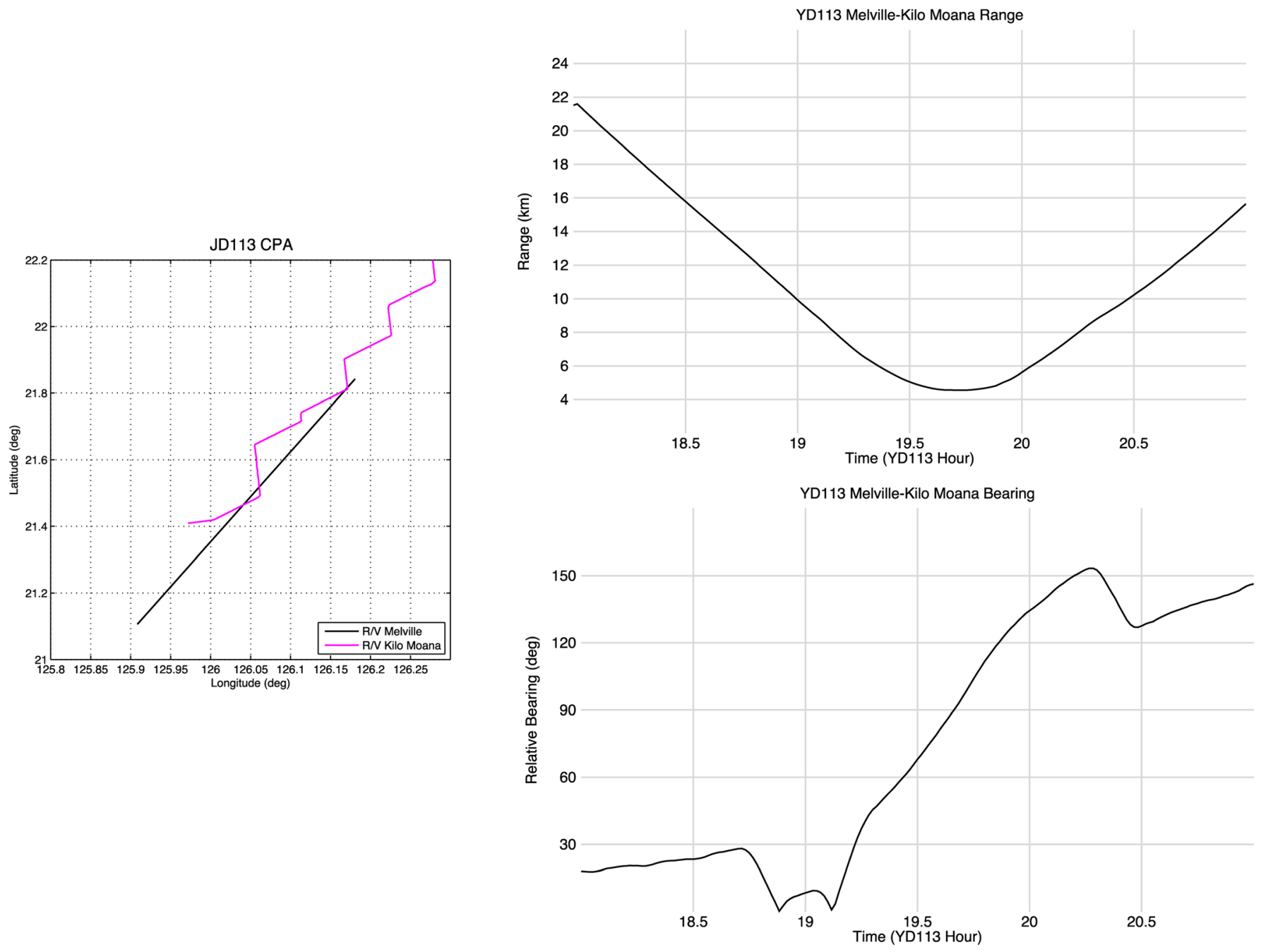

FIG. 2. (Color online) (Left) R/V Melville and R/V Kilo-Moana positions during JD113 2009. Source-receiver range (upper right) and relative bearing (lower right) for the $3 \mathrm{~h}$ nearest CPA at $1945 \mathrm{UTC}$.

due to our transmitted signal and will be shown to be the bottom bounce. The signal-to-noise ratio (SNR) at the higher frequencies is better because of the reduced surface shipping noise (Urick, 1967). In Fig. 4, the closing CZ crossing is observed at 1430 UTC. A central feature of this paper is the examination of the source energy that arrives at nearly all ranges within the $\mathrm{CZ}$ at bearings that do not correspond to the source location.

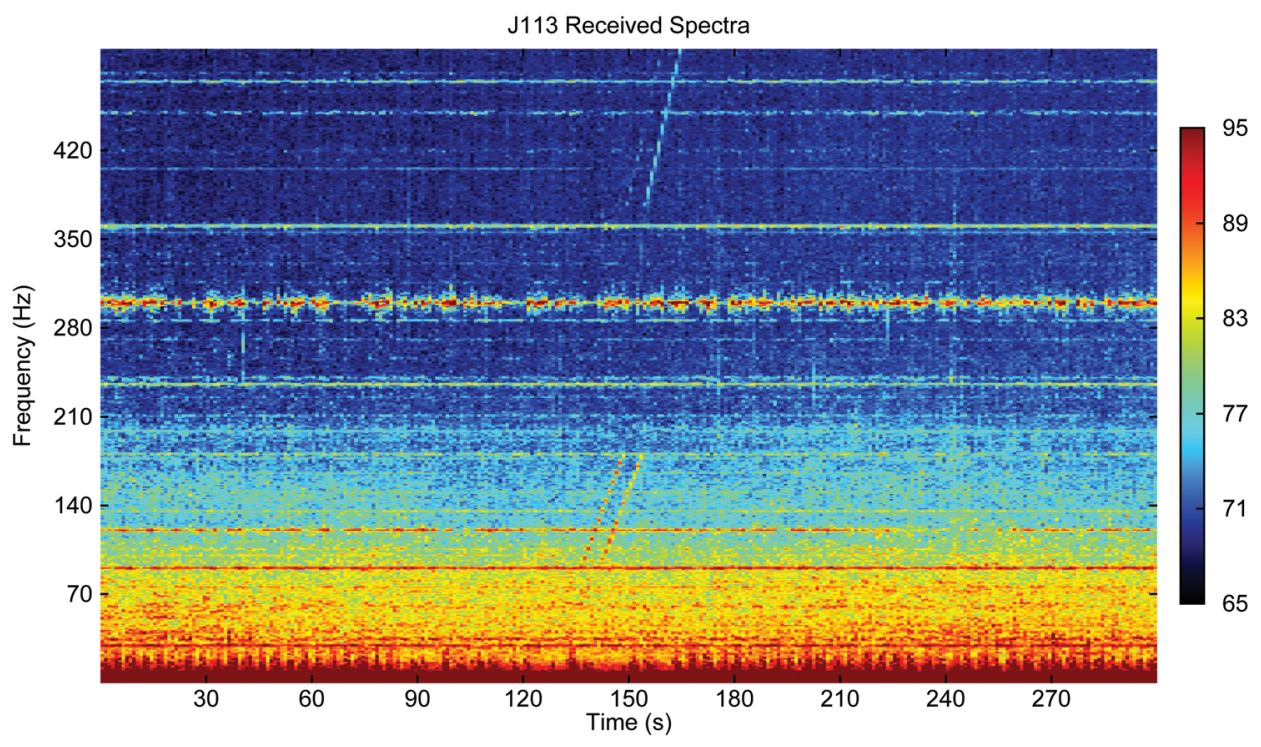

FIG. 3. (Color online) Phone averaged spectrogram for JD113 portion of NPAL PhilSea09. Narrowband transmitted frequencies are $79,100,135$, 198, 355, and $405 \mathrm{~Hz}$. The two LFMs are $90-180$ and $375-525 \mathrm{~Hz}$. Units are in $\mathrm{dB}$ re $1 \mu \mathrm{Pa}^{2} / \mathrm{Hz}$. 


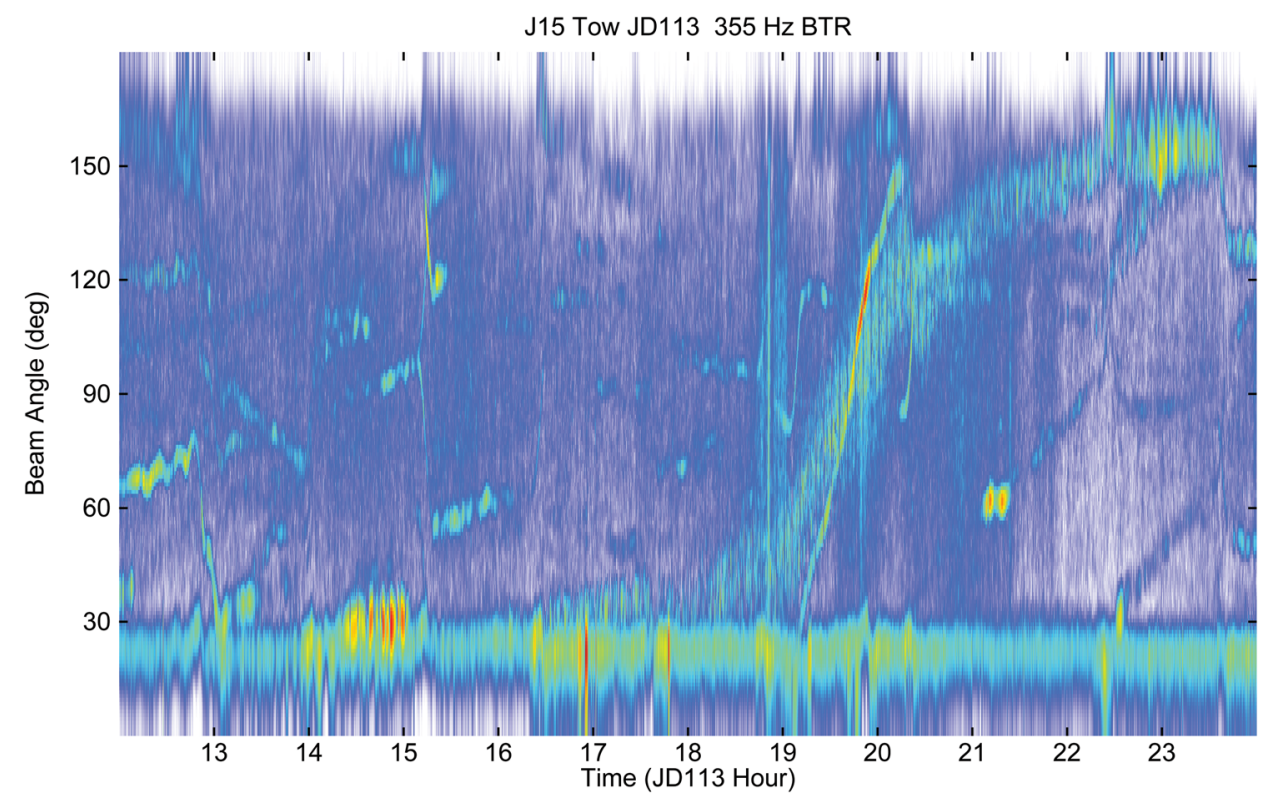

FIG. 4. (Color online) Narrowband $(355 \mathrm{~Hz})$ bearing time record for jd113 (2009) 1200Z-2400Z during the R/V Melville and R/V Kilo Moana crossing (1945Z). The CZ, direct path, and bottom bounce arrivals are all evident. Units are in decibels relative to the peak.

a)

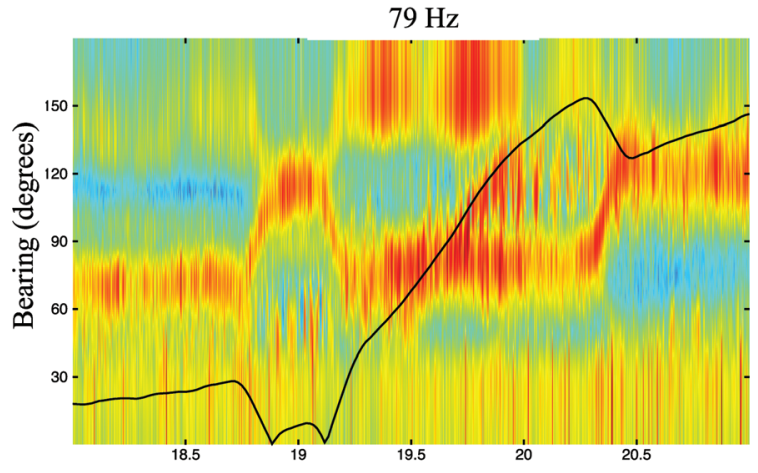

c)

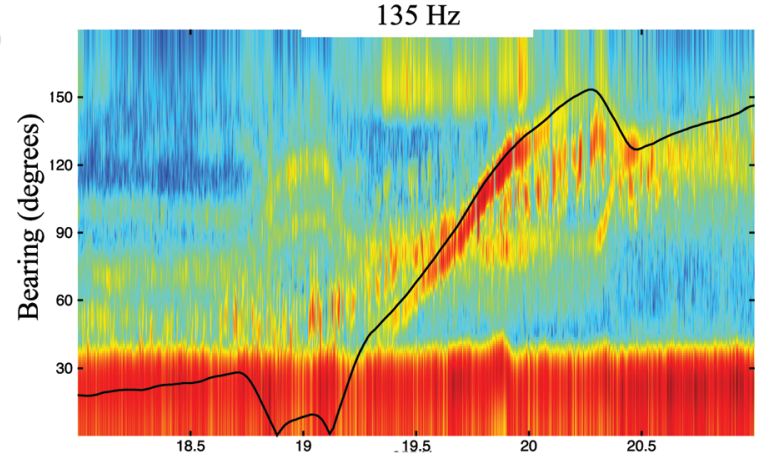

e)

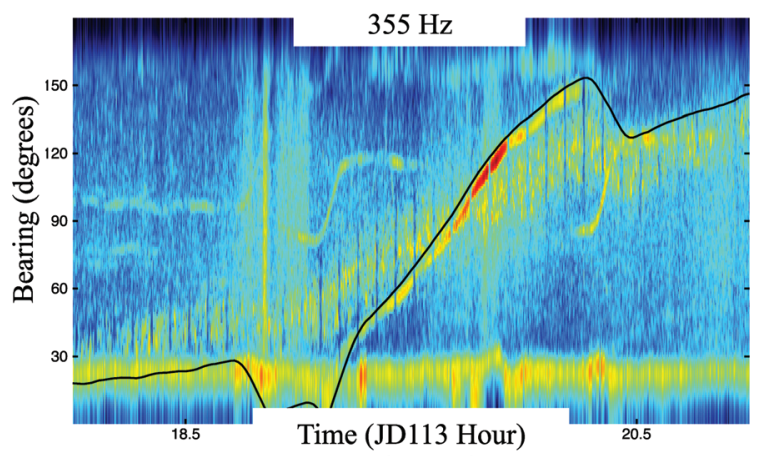

b)

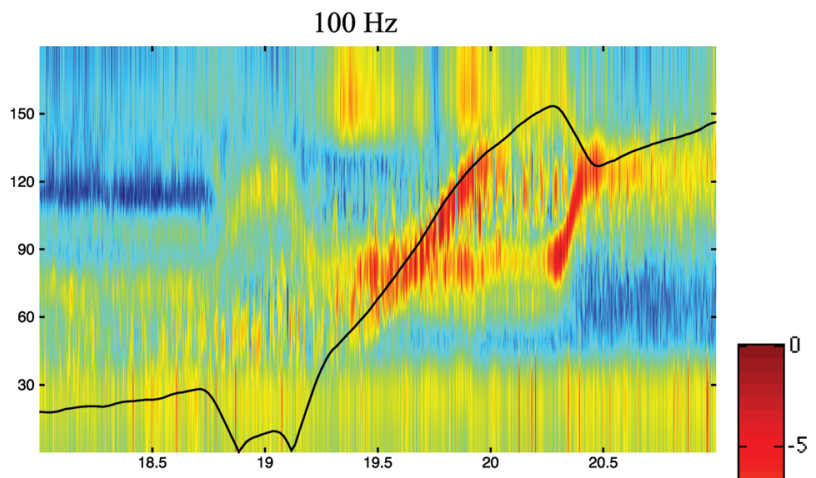

d)

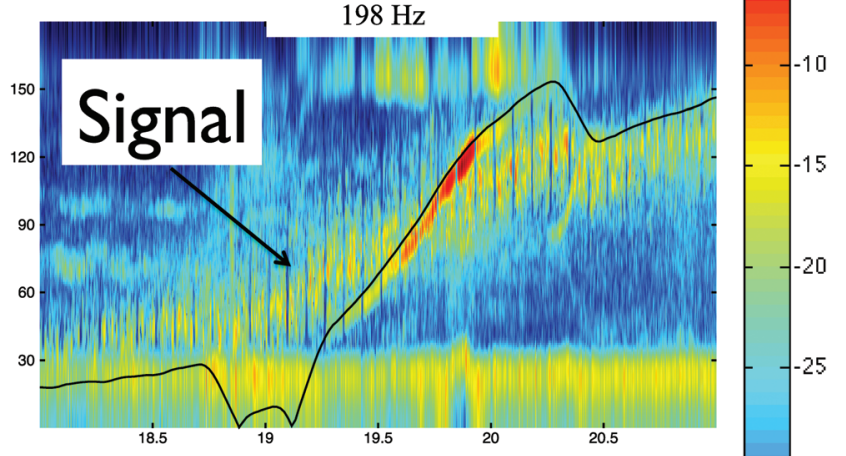

f)

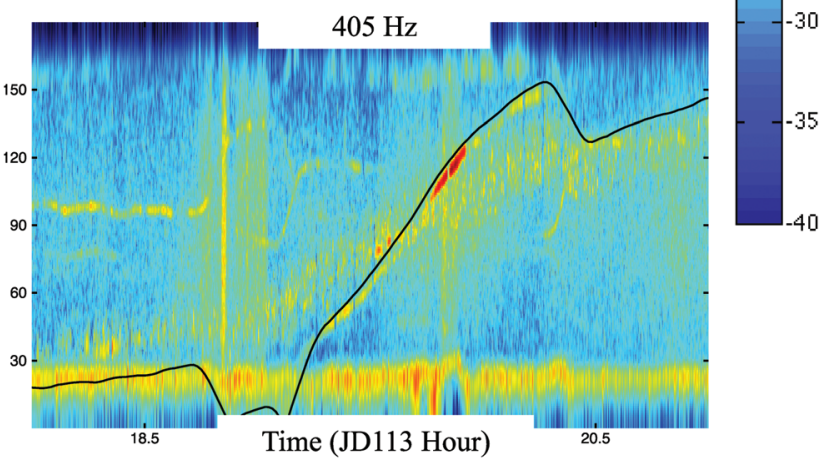

FIG. 5. Narrowband bearing-time record for jd113 (2009) 1800 UTC-2100 UTC during the R/V Melville and R/V Kilo Moana crossing (1945Z). Frequencies are (a) $79 \mathrm{~Hz}$, (b) $100 \mathrm{~Hz}$, (c) $135 \mathrm{~Hz}$, (d) $198 \mathrm{~Hz}$, (e) $355 \mathrm{~Hz}$, and (f) $405 \mathrm{~Hz}$. The dynamic range is $40 \mathrm{~dB}$ relative to the maximum, which is frequency dependent but on the order of $80 \mathrm{~dB}$ re $1 \mu \mathrm{Pa}^{2} / \mathrm{Hz}$. 


\section{NARROWBAND BEAM RESPONSE}

\section{A. Measurements}

We begin by looking at the narrowband beam response during the $3 \mathrm{~h}$ surrounding the CPA. Propagation ranges are within $25 \mathrm{~km}$ during this time period. To analyze the narrowband tones, the $8 \mathrm{kHz}$ data are basebanded for each of the transmitted frequencies and resampled with a $4 \mathrm{~Hz}$ sample rate. The array data are spatially Hann-windowed and a plane wave time-domain beamformer is applied (181 uniformly spaced beams). A $25 \mathrm{~s}$ (100 sample) Fouriertransform is taken and the maximum over frequency is plotted. The 3-h BTR for each of the strong transmitted tones is shown in Fig. 5. At the higher frequencies, with greater SNR and beam resolution, the identification of the transmitted tone is easily made by the on-off nature of the signal due to the drop in narrowband transmission energy during the broadband LFM signals.

The lower frequencies, particularly 79 and $100 \mathrm{~Hz}$, are dominated by directional energy, interpreted as surface ship ambient noise. The relative background noise field drops significantly at frequencies of 198,355 , and $403 \mathrm{~Hz}$. The tow-ship radiated noise of the R/V Kilo Moana is evident at all frequencies, especially at $355 \mathrm{~Hz}$. Note that at the higher frequencies, the own-ship noise comes in near $25^{\circ}$ due to the depth of the array. The technique of approaching the R/V Melville at $\pm 15^{\circ}$ off forward endfire was successful in moving the signal energy out of the forward endfire beam. Signal energy from the J-15 is easily identified by the on-off vertical striations observed during the $30 \mathrm{~s}$ of the LFM sweep every $300 \mathrm{~s}$. During these periods, there is little source energy within the $4-\mathrm{Hz}$ band of the transmitted tones. Source energy can be classified into two groups, direct path and bottom bounce. The first group of energy has a high bearing rate, fades at longer ranges, peaks at CPA, and corresponds closest to the true bearing of the source. This is interpreted as the direct path propagation from the J15 to the FORA array, including the surface bounce. This energy falls off with range as the receiver moves into the acoustic shadow associated with shallow source/receiver combinations in deep water with downward refracting profiles. The second group of energy arrives at a)
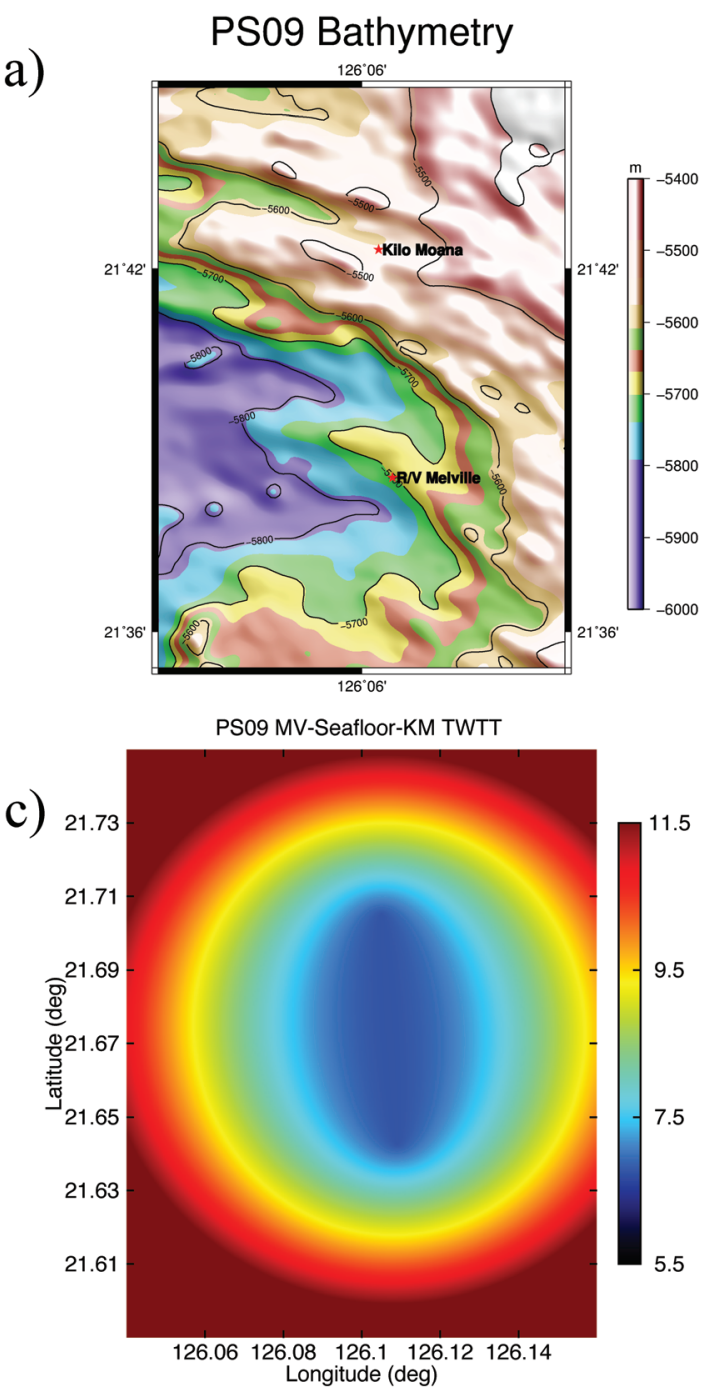

b)

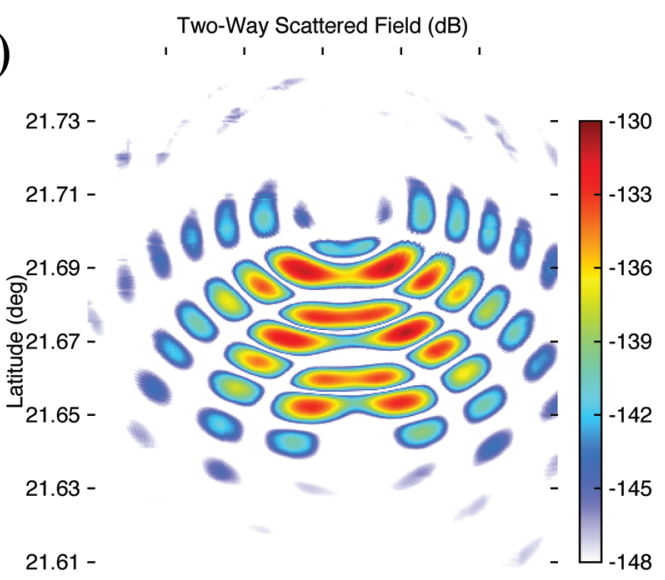
$126^{\prime} .06 \quad 126.08 \quad 126^{\prime} .1$
Longitude (deg)

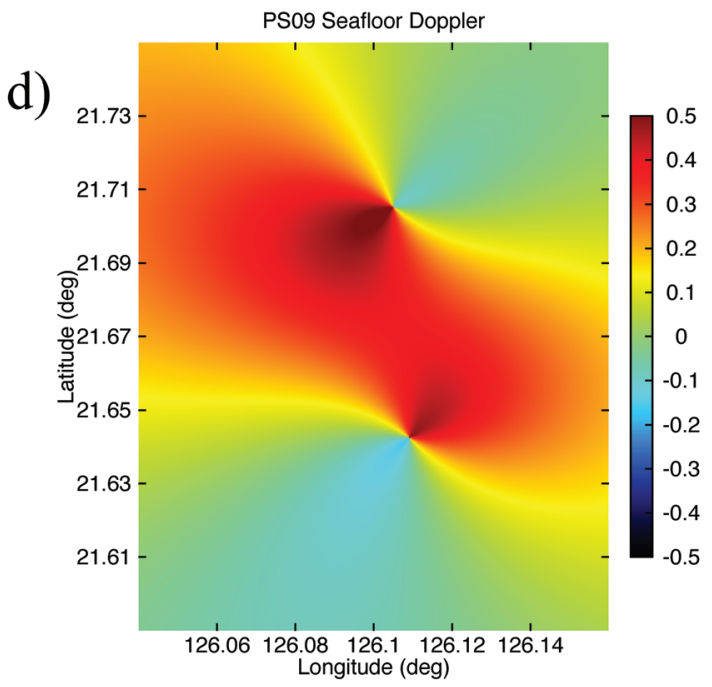

FIG. 6. Geometry example of seafloor reverberation: (a) Bathymetry and R/V Kilo-Moana, R/V Melville at 1915Z on JD113. (b) Energy returned from each patch of seafloor-this is the two-way TL multiplied by a 3D scattering kernel. (c) Two-way travel time ellipse. (d) Doppler ridges combining both moving source and receiver. 
all ranges (within this $3 \mathrm{~h}$ window), is spread over $30^{\circ}$ of angle and has a lower bearing-rate. It is observed closer to broadside than the true source bearing. This group of energy is associated with both in-plane and out-of plane bottom bounce energy. Within this energy will be surfacebottom interacting energy as well.

\section{B. Parabolic equation modeling}

To interpret the arrivals and determine the relative importance of bathymetry, surface roughness and out-of-plane propagation, we perform PE modeling of the CPA event. For each of the processing streams presented in Sec. III A, a set of high-resolution Nx2D PE model runs was performed. The PE model used is CRAM, a C-language based reformulation of the split-step Pade Parabolic equation RAM (Collins, 1993). CRAM permits acoustic field synthesis from a source to individual array elements in an efficient manner with an automatically determined or user-defined cross-range tolerance reflecting the expected cross-range variation in the input and output fields. In this case, the field is computed every minute over a 3-h period with a cross-range tolerance of $100 \mathrm{~m}$. The range-independent SSP shown in Fig. 1 is used. The bathymetry is modeled both as a flat seafloor $(5550 \mathrm{~m})$ and from the measured and merged multi-beam surveys from both ships. When included, surface waves are explicitly added using a 3-m significant wave height field incident from the northwest with a dominant wave period of $12 \mathrm{~s}$. The method for inclusion of surface roughness follows that of Collins'
RAMSURF variant of the PE. The geoacoustic parameters used for the model were estimated from a brief review of the geological literature in the area, including the taking of several core samples as described in the appendix. The geoacoustic model is bathymetry following. This model is fluidfluid and only supports compressional waves. The examination of the impact of shear on the seafloor reflection is beyond the scope of this work. The PE parameters used were 16 points per wavelength in depth at the highest frequency used, and five wavelengths per point in range. The number of Pade coefficients used was 10 at the origin, falling off gradually to four coefficients within one convergence zone. For every minute of the $3 \mathrm{~h}$ nearest CPA, the model is run using the source position and array element positions. The full array pressure field is Hann-windowed and plane-wave beamformed following the procedure used to generate Fig. 5. This analysis was completed for all the transmitted frequencies. The $355 \mathrm{~Hz}$ results are shown because of this frequency had the highest SNR.

To guide discussion about in-plane and out-of-plane propagation within the context of bottom reverberation, the geometry of the seafloor reflection and reverberation is discussed. The geometry used for illustration is taken at time $1915 Z$ on JD113 as the R/V Kilo-Moana is closing on the $\mathrm{R} / \mathrm{V}$ Melville prior to CPA. The offset distance (from Fig. 1) is $7 \mathrm{~km}$. The position of the two ships, overlaid on the highresolution multi-beam bathymetry is shown in Fig. 6(a). The predicted return from each patch of the seafloor is shown in Fig. 6(b). Narrowband PE modeling (frequency $=100 \mathrm{~Hz}$ ) is a)

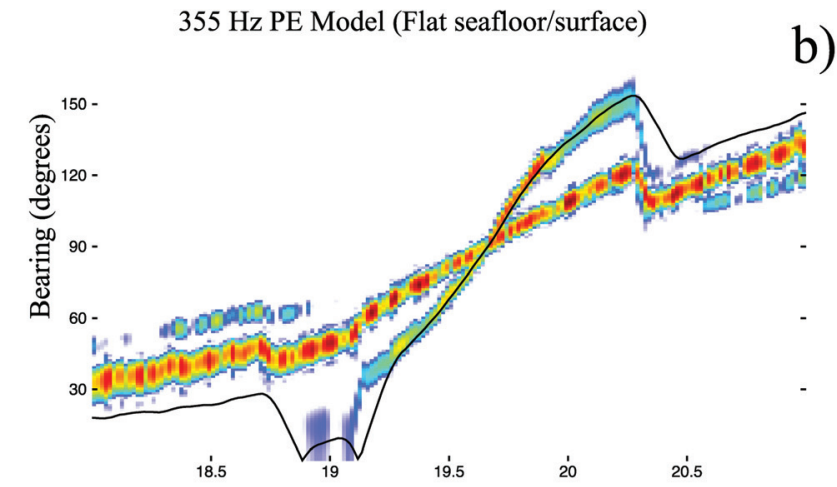

c)

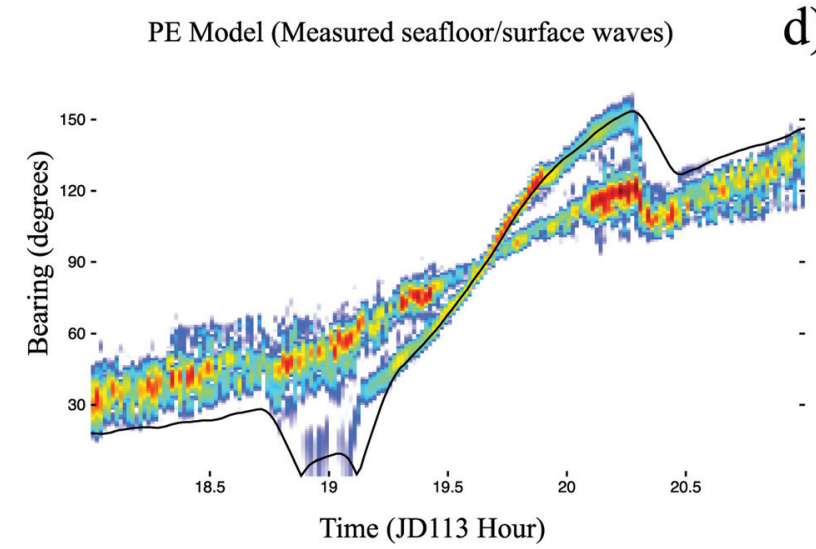

b)

d)
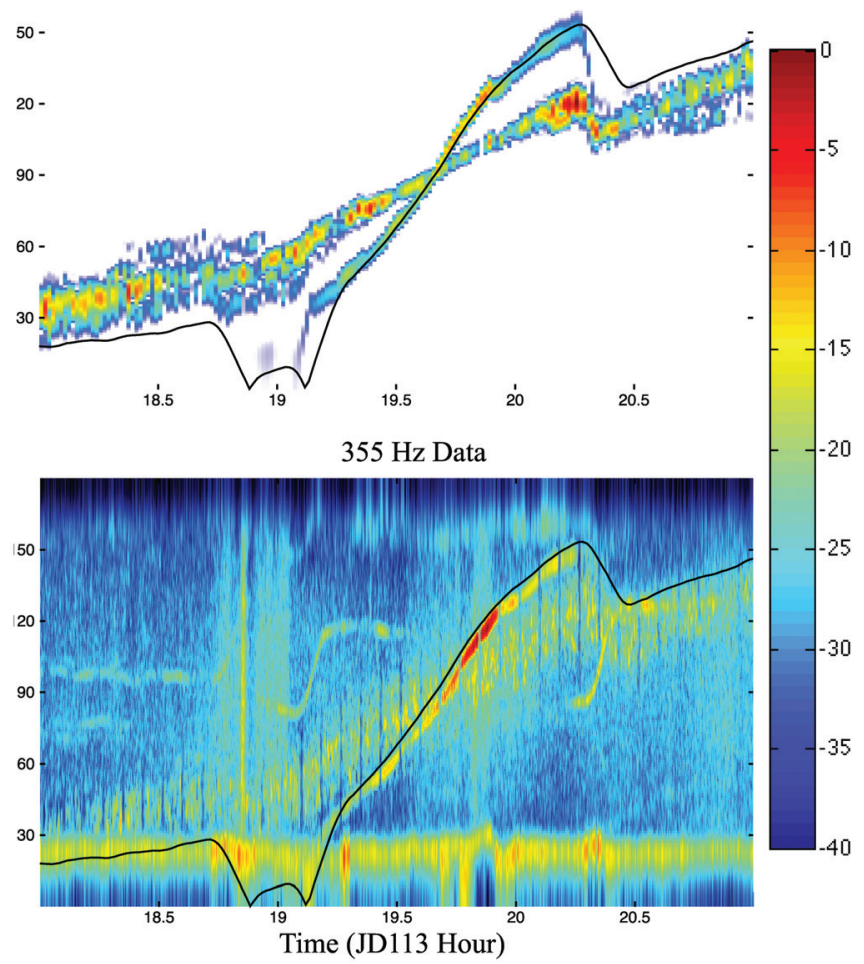

FIG. 7. $355 \mathrm{~Hz}$ bearing-time response for $3 \mathrm{~h}$ near CPA. (a) PE model using measured source/hydrophone positions and flat seafloor (5550 m) and flat sea surface. The source-receiver bearing is drawn over the model results. (b) PE result with measured bathymetry. (c) PE result with measured bathymetry and surface waves. (d) Measured bearing-time-record. Units are in decibels relative to the peak. 
performed from the source and each element of the FORA array (then power averaged) to each patch of the seafloor (roughly $45 \mathrm{~m} \times 45 \mathrm{~m}$ ). With the source at $60 \mathrm{~m}$ and the array at $120 \mathrm{~m}$, the bi-static TL is a super-position of two radially symmetric Lloyd mirror patterns. To take into account the incoming and outgoing energy via a scattering Kernel, the Ellis and Haller (Ellis and Haller, 1987) model was applied:

$$
\begin{aligned}
& S\left(\theta, \theta^{\prime}, \phi\right)=\mu \sin \theta \sin \theta^{\prime}+\nu(1+\Delta \Omega) e^{-\left(\Delta \Omega / 2 \sigma^{2}\right)} \\
& \Delta \Omega=\frac{\left(\cos ^{2} \theta+\cos ^{2} \theta^{\prime}-2 \cos \theta \cos \theta^{\prime} \cos \phi\right)}{\left(\sin \theta+\sin \theta^{\prime}\right)^{2}},
\end{aligned}
$$

where $\theta$ and $\theta^{\prime}$ are the vertical incident angle $\left(16^{\circ}\right.$ in this environment) on the seafloor, $\phi$ is angle between source and receiver at the patch, $\mu(-30 \mathrm{~dB})$ is the LambertMackenzie (Urick, 1967) diffuse scattering parameter, and $\nu$ $(-25 \mathrm{~dB})$ is the out-of-plane scattering parameter characterized by a width $\sigma\left(35^{\circ}\right)$. The two-way travel time, from the source to the seafloor to the receiver, is plotted in Fig. 6(c) showing the standard ellipses. The in-plane bottom bounce arrives at $5.5 \mathrm{~s}$. This figure demonstrates that there is expected to be significant energy from out-of-plane in addition to the $2 \mathrm{D}$ in-plane path containing the specular reflection. The final geometric figure is the Doppler-ridge plot for a moving source and receiver. This computation is for a frequency of $355 \mathrm{~Hz}$. At this time most of the seafloor that is well illuminated [Fig. 6(b)] is in the positive Doppler region as expected. Near CPA, however, there will be a significant both positive and negative Doppler. This is evident in the data, presented in Sec. IV.

The first model results presented in Fig. 7(a) are for a flat bathymetry without surface waves. The true bearing to the $\mathrm{R} / \mathrm{V}$ Melville is shown as the overlaid black line. The direct path propagation, which closely follows the true bearing, and the bottom bounce paths are clearly visible. The direct-path arrival is clear from hours 19.2 to 20.1 when ranges are less than $7 \mathrm{~km}$. The strong specular bottom bounce is clear as the strong energy arriving closer to broadside than the direct path. The weaker arrivals at hour 18.3-18.7 and beyond 26.4 are interpreted as a surfacebottom bounce. The second PE computation, shown in a)

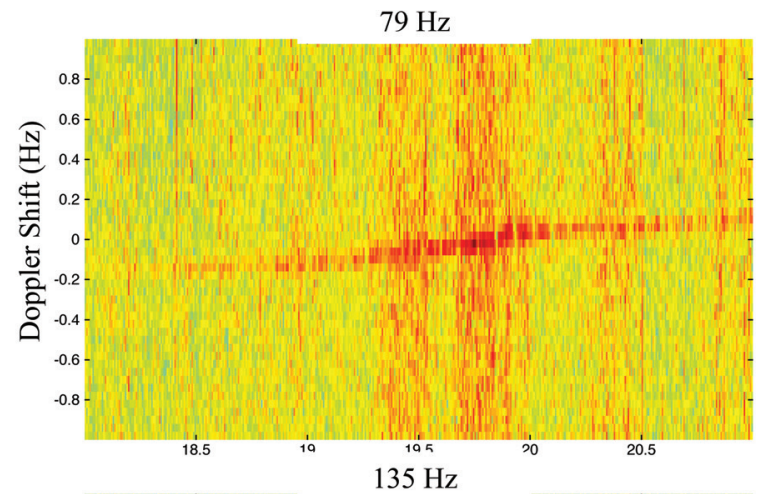

c)

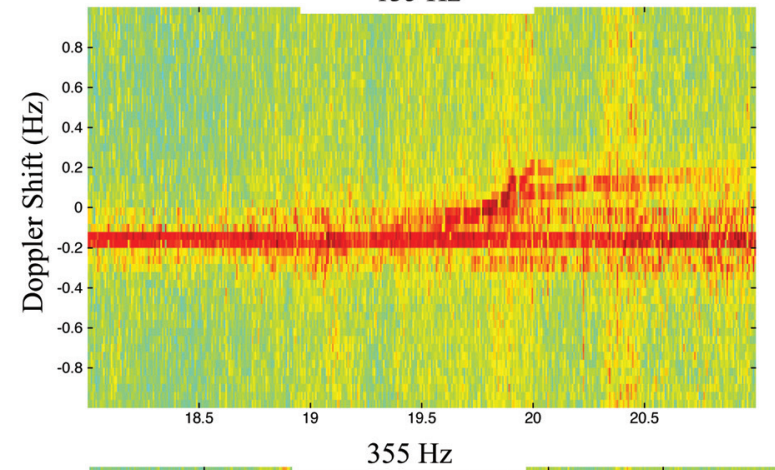

e)

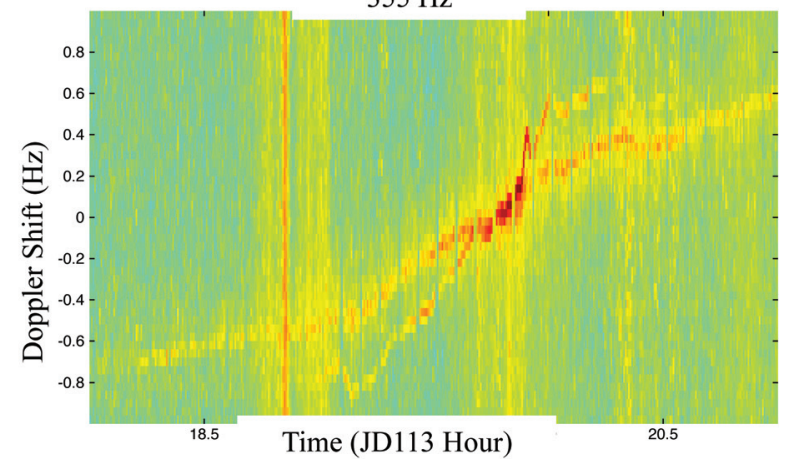

b)

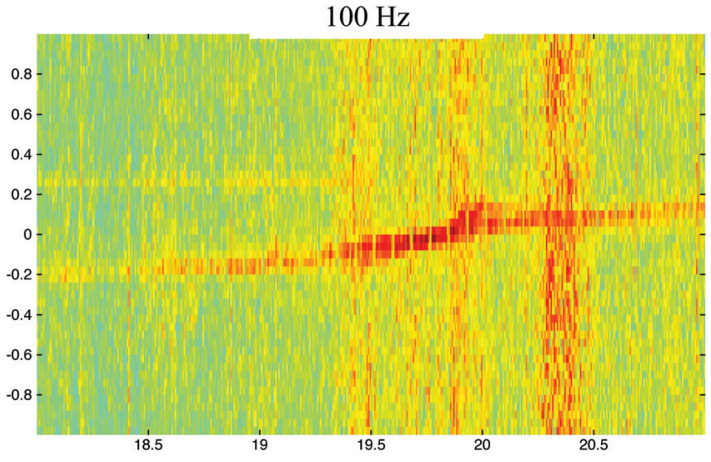

d)

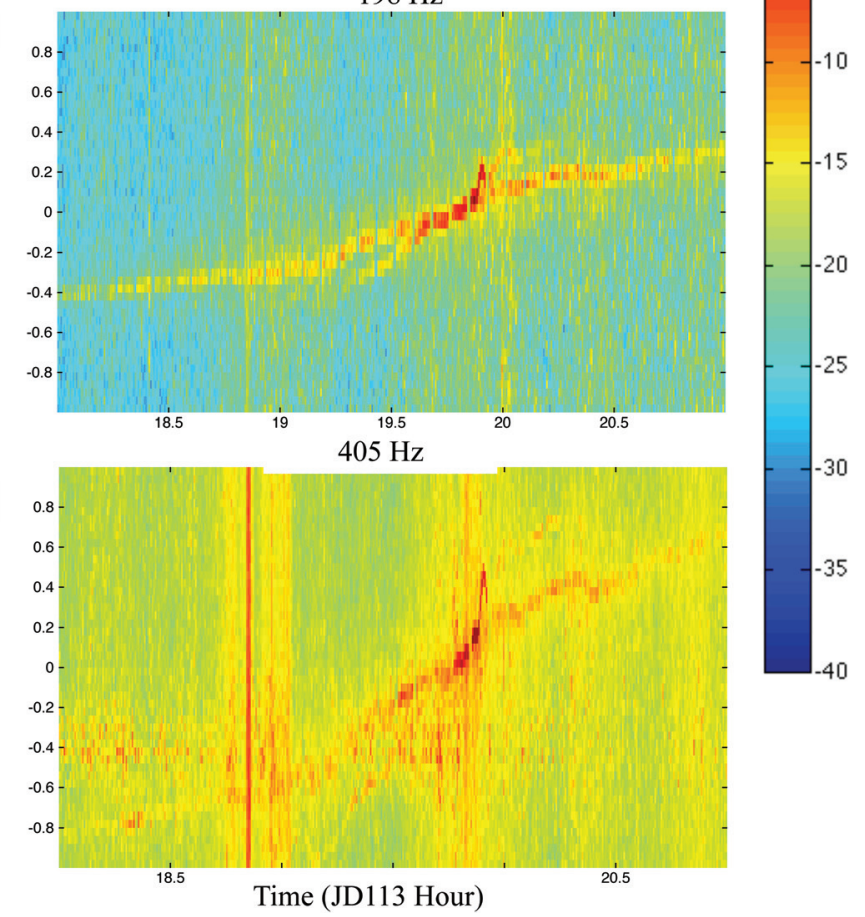

FIG. 8. Phone averaged Doppler time record for $3 \mathrm{~h}$ near JD113 CPA for frequencies $79-405 \mathrm{~Hz}$. At higher frequencies, the direct path and bottom bounce paths are evident. Units are in decibels relative to the peak. 
Fig. 7(b), uses the measured bathymetry, keeping the surface of the ocean flat. This result demonstrates how the bottom roughness ( $\sim 50 \mathrm{~m}$ resolution) breaks up the specular nature of the arrival, both in strength and scatter in arrival angle. The surface-bottom bounce at hour 18.6 is visible but significantly weaker. The inclusion of bottom and surface roughness, through an explicit frozen surface wave realization, is shown in Fig. 7(c). The surface wave realization spreads the bottom bounce angles of arrival, almost eliminates the surface-bottom bounce, and increases the level of energy returning from the seafloor. For comparison, the measured BTR for the $355 \mathrm{~Hz}$ data is shown in Fig. 7(d). The Nx2D PE computation reproduces the direct arrival, the locations of the bottom bounce energy, and some of the spread in the bottom bounce vertical angle of arrival. It overestimates the strength and tightness of the bottom bounce arrival. The overestimation of the bottom bounce could be due to inaccuracies in the geoacoustic model, but it is also a result of the $2 \mathrm{D}$ approximation. Conservation of energy requires that all energy incident on the seafloor either transmit into the sediment or reflect back into the ocean. For a 3D rough seafloor, energy can scatter out of plane. Neglecting this feature can overpredict the specular reflection strength. The larger bearing spread of the bottom reflection, particularly near CPA, is evidence of out-of-plane scattering, which is not included in the PE model.

\section{NARROWBAND DOPPLER RESPONSE}

\section{A. Measurements}

Analysis of the narrowband beam responses has revealed a clear distinction between the direct path arrivals and the boundary interacting energy. A greater than $20^{\circ}$ spread is observed for the bottom interacting paths. To differentiate between energy that is vertically scattered in the 2D source-receiver plane and energy that is out of plane, we examine the Doppler spread of the received signal. The processing involves high-resolution spectral processing, followed by magnitude squared hydrophone averaging and short time interval temporal averaging. The hydrophone averaged Doppler time record for each frequency is shown in Fig. 8.

In each record, the high bearing rate and received level of the direct path Doppler shift are visible. Also clear is the broad Doppler spread of the bottom bounce energy. As the two research vessels approach each other, at an oblique angle, scattering from the seafloor inside of the angle of approach has an increased Doppler shift. Scattering from seafloor regions outside of the angle of approach has a smaller and possibly negative Doppler shift (Cox, 1996). For in-plane propagation, the Doppler changes with the vertical angle of arrival.

\section{B. Parabolic equation modeling}

The Doppler spread of in-plane propagation using the Nx2D PE is now examined. The narrowband acoustic pressure field was computed for propagation from the $\mathrm{R} / \mathrm{V}$ Melville to a densely sampled vertical line array at the position of the R/V Kilo Moana. The receiver locations were
1 -m spaced in the vertical from 250 to $300 \mathrm{~m}$. Hannwindowed plane-wave beamforming was performed in the vertical. As in the previous section, the model was run for three environments, range independent, measured bathymetry, and measured bathymetry with surface waves. The vertical directionality as a function of time for each of the three environments is shown in Fig. 8. The two arrival paths are clear with the direct path arriving near zero grazing-angle at ranges within $7 \mathrm{~km}$. The clear bottom bounce as well as the surface-bottom bounce is seen in Fig. 9(a). The inclusion of bottom roughness [Fig. 9(b)] via the measured bathymetry breaks up the specular reflection and washes away the surface-bottom bounce. Addition of a rough sea surface spreads the vertical angle of the arriving bottom bounce. Scattering into all downward propagating angles occurs at short range, as the scattering from a single surface bounce is visible. Note the times (locations) of the surface-bottom bounce arrivals are slightly different in Figs. 8(a) and 8(b). The $5550 \mathrm{~m}$ range-independent water depth is not quite correct during the initial closing. At this location, the water is deeper, leading to a different location of the specular reflection.

To compute the Doppler spread, the source-receiver closing speed and the vertical angle of arrival of the acoustic energy must be computed. For a given closing speed $v$ and angle of arrival $(\phi)$ the Doppler shift is given by:

a)

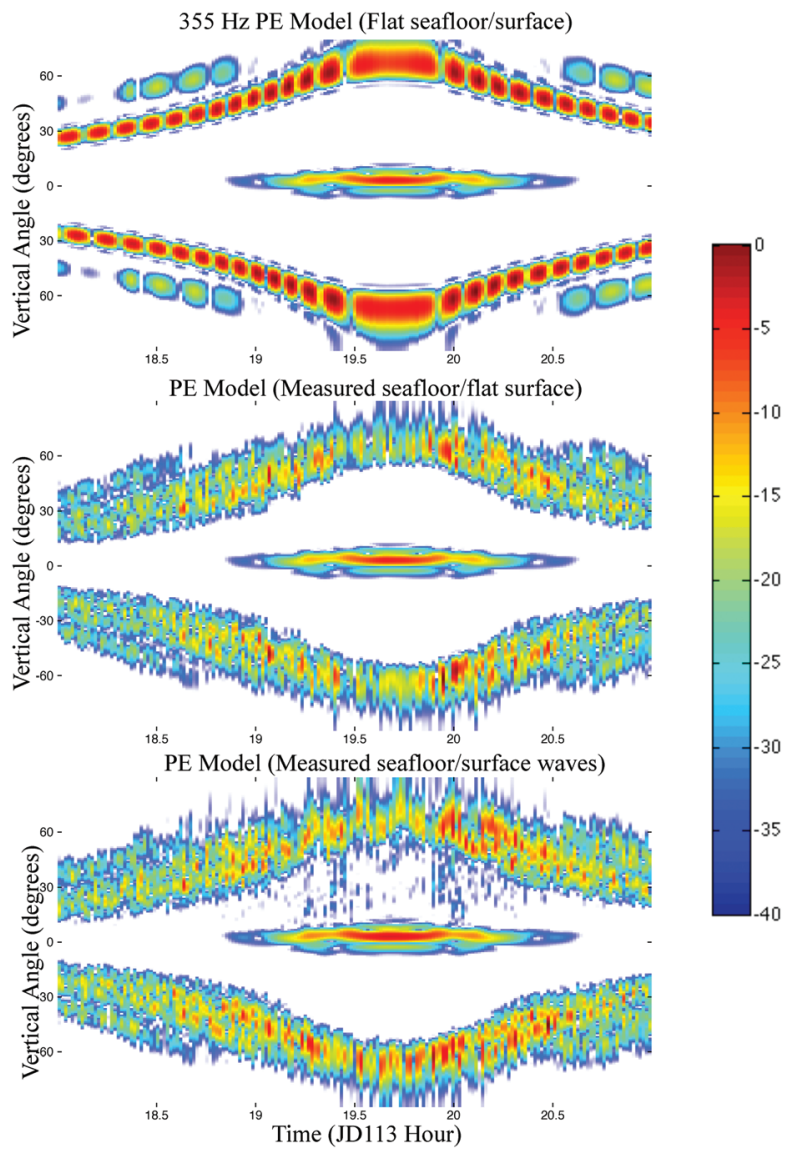

FIG. 9. Vertical directionality vs time (hour) for three parabolic equation model runs. (a) Range-independent, (b) measured bathymetry, and (c) measured bathymetry with surface roughness. The units are decibels relative to the peak. 


$$
\Delta f \sim f_{0} \frac{v \cos \phi}{c_{\text {water }}} .
$$

For each vertical angle $(\phi)$, the Doppler is computed and a power sum over Doppler is performed. The $355 \mathrm{~Hz}$ results are shown in Fig. 10 for the three Nx2D environments described in the preceding text and for the measurement. As in the BTR results of Fig. 7, the measured seafloor roughness breaks up the strong specular arrival. There is evidence of a symmetric Doppler ridge in the data for the bottom bounce (some scatter of the bottom bounce is to higher Doppler, some is to lower). Out-of-plane scattering is evident in the measurement near CPA. As the ships approach each other at short ranges, there is nothing in the acoustic model presented in Eq. (2) that can lead to negative Doppler. The cosine term can only reduce the positive Doppler. For out-of-plane propagation, however, sound can go beyond the receiver and bounce back, leading to a negative Doppler, even though the source and receiver are approaching each other. The receiver in this geometry is moving away from the scattering patch on the seafloor.

\section{BROADBAND IMPULSE RESPONSE}

\section{A. Measurements and modeling}

The narrowband response curves so far demonstrate that it is difficult to disambiguate out-of-plane scattering from rough interface scattering in the source-receiver plane. Direct, bottom bounce, and out-of-plane scattering are most easily identified in the broadband impulse response of shortrange transmissions. We now present the beam-matched filter results. To examine the low-frequency LFM transmission, the element level data are basebanded to $90 \mathrm{~Hz}$ sample rate around the center frequency of $135 \mathrm{~Hz}$. These data are spatially Hann-windowed and conventional plane-wave beamforming is applied. Each beam is convolved with the transmitted LFM replica. During the JD113 ship-crossing event, the $\mathrm{R} / \mathrm{V}$ Melville is underway, generating a large amount of ambient noise near the source location. During JD111, a CPA event occurred where the R/V Kilo Moana approached the stationary R/V Melville to within a $1.8-\mathrm{km}$ $\mathrm{CPA}$. The transmitted tone sequence was modified at CPA, so there is only a closing. A single LFM beam-time series, close to the CPA is presented in Fig. 11.

The measured beam-impulse response [Fig. 11(d)] clearly shows the direct path (with an associated surface bounce) and $7 \mathrm{~s}$ later the bottom bounce path. The direct arrival comes in at $110^{\circ}$ and the seafloor returns centered at broadside $\left(90^{\circ}\right)$, corresponding to the arrivals from directly below the array. The measured bottom bounce arrival lasts $1.5 \mathrm{~s}$ and is spread over $30^{\circ}$ forward and aft. The PE model shown in Fig. 11(a) is computed with a flat sea surface and seafloor. The direct path arrival, as well as the bottom bounce and bottom-surface bounces, arrive at the expected angles and times. The addition of seafloor roughness [Fig. 11(b)], via the measured multi-beam bathymetric data, scatters the bottom bounce arrival in time, more so than in angle. Inclusion of surface roughness only impacts the

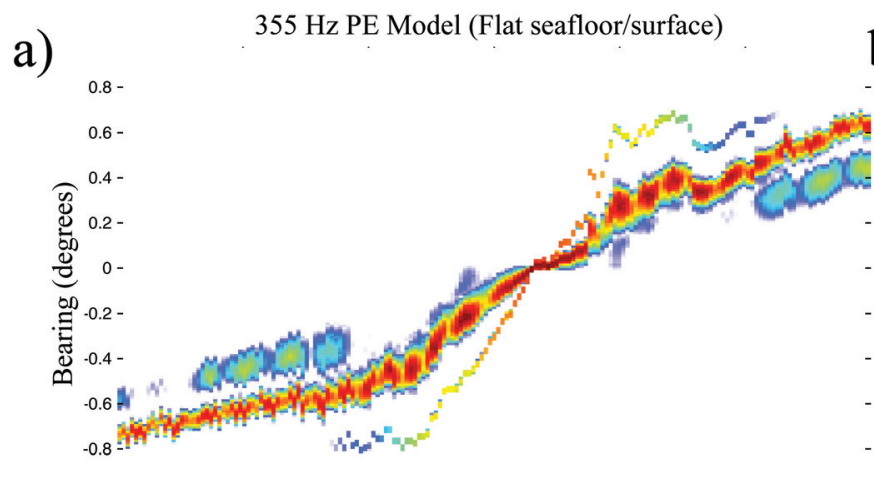

b).8-

PE Model (Measured seafloor/flat surface)

c)
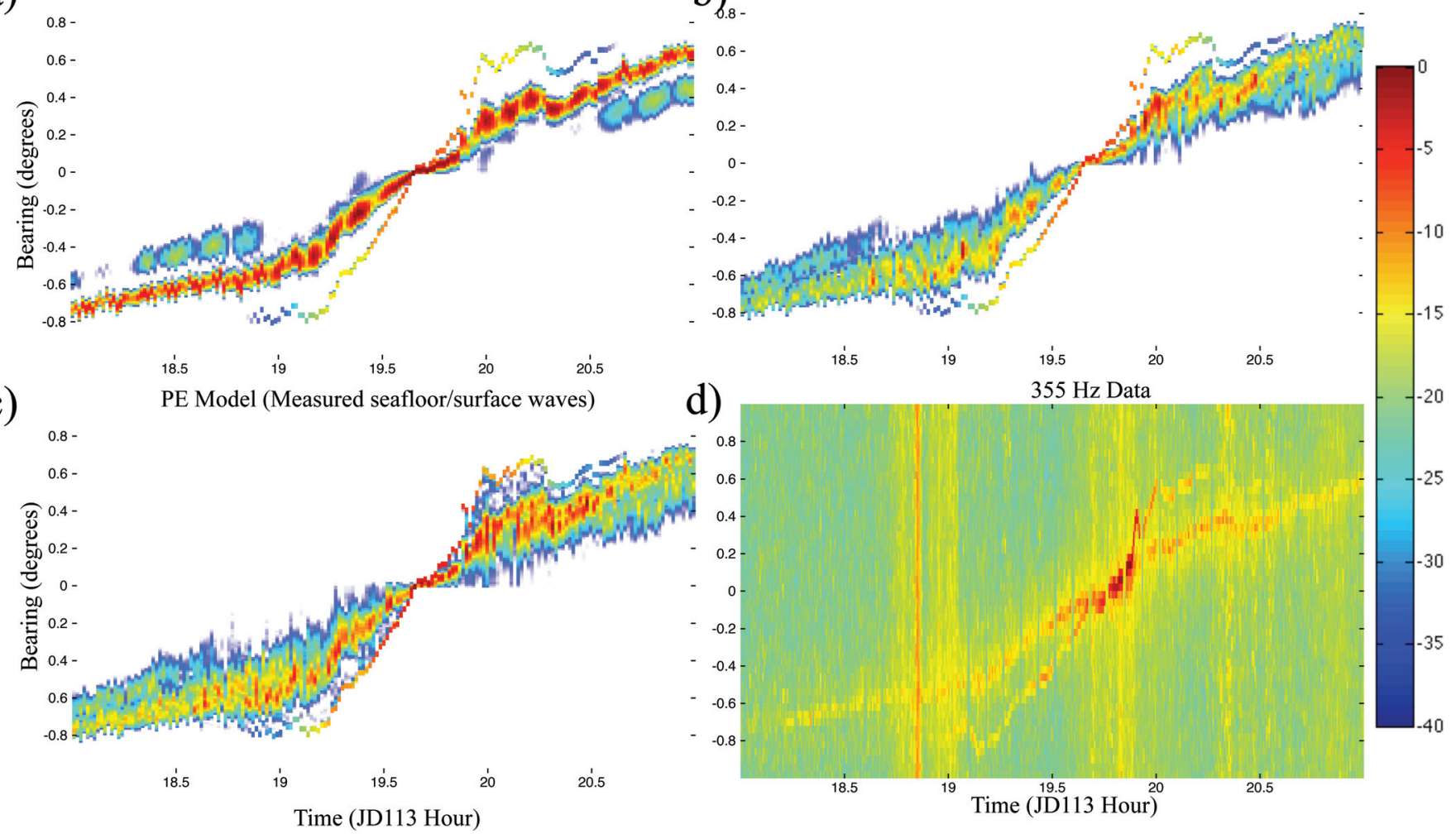

FIG. 10. $355 \mathrm{~Hz}$ Doppler time response for $3 \mathrm{~h}$ near CPA. (a) PE model using measured source/hydrophone positions and flat seafloor (5550 m) and flat sea surface. (b) PE result with measured bathymetry. (c) PE result with measured bathymetry and surface waves. (d) Measured Doppler time record. Units are in decibels relative to the peak. 
a)

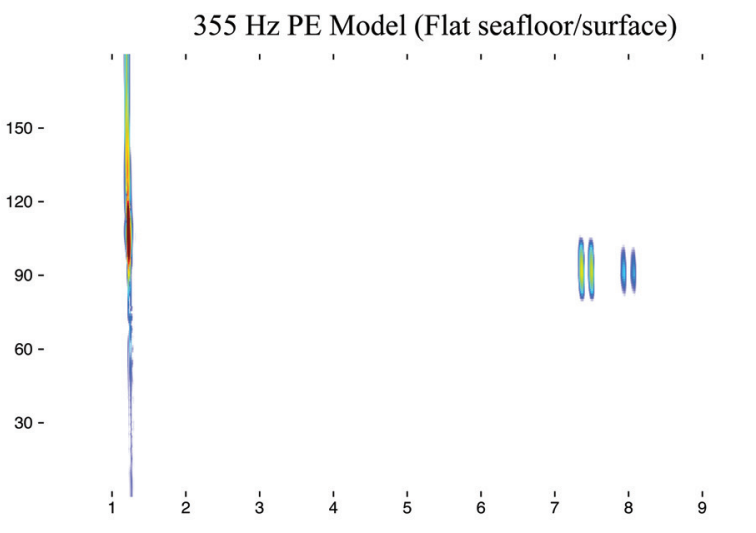

PE Model (Measured seafloor/surface waves)

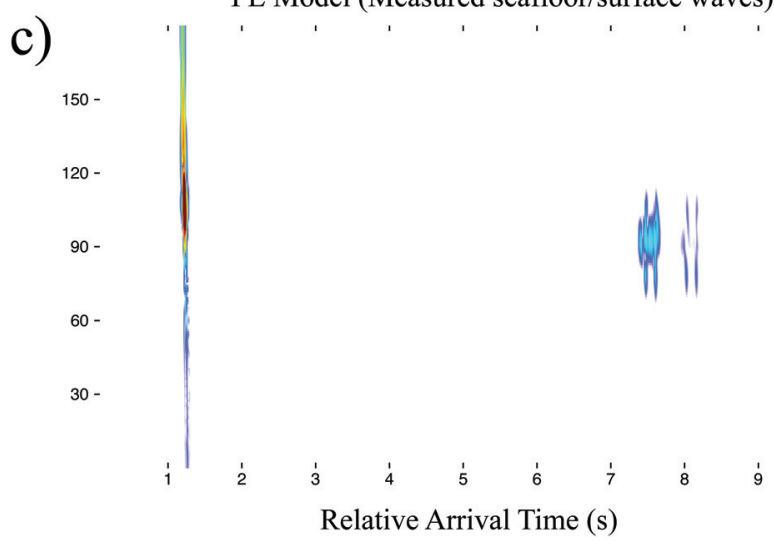

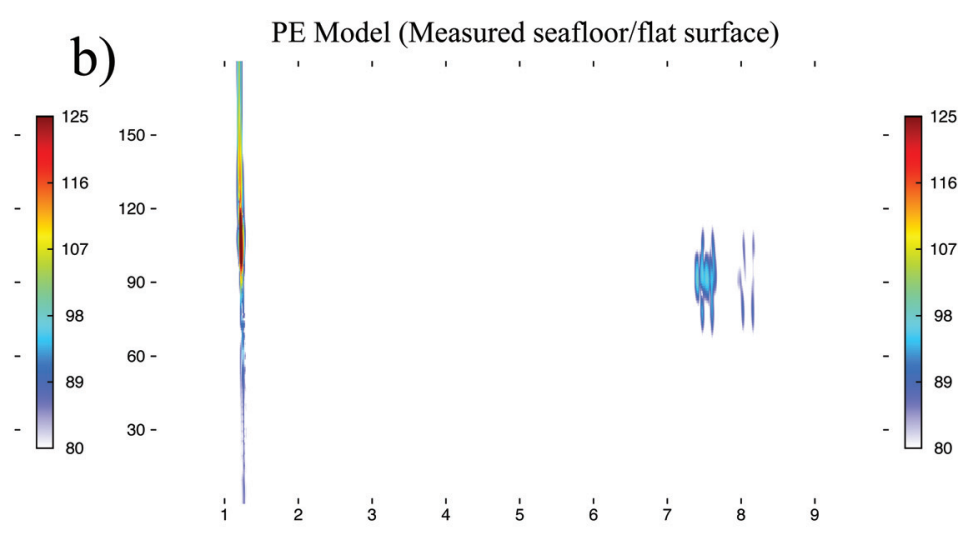

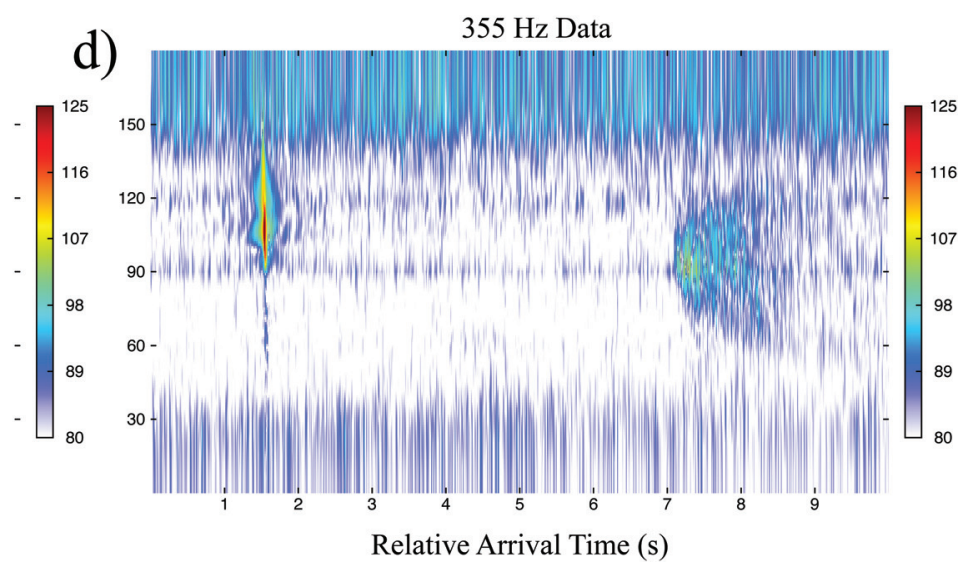

FIG. 11. Broadband impulse response vs bearing near CPA showing direct path and bottom bounce arrivals. (a) Data. (b) PE model with flat surface/seafloor. (c) PE model with flat surface, measured seafloor. (d) PE model with waves and measured seafloor. Units are in $\mathrm{dB} \mathrm{re} 1 \mu \mathrm{Pa}^{2} / \mathrm{Hz}^{2}$

bottom bounce spread slightly. The conclusions are that inplane roughness is not able to explain the time and spatial extent of the bottom returns.

\section{SUMMARY AND CONCLUSION}

In this paper, short range $(<65 \mathrm{~km})$ towed array recordings of narrowband and broadband signals in deep water are presented. The experiment involved the passing of a source ship (R/V Melville) and a tow ship (R/V Kilo Moana) in $5500 \mathrm{~m}$ of water in the Philippine Sea during the NPAL PhilSea09 experiment in April 2009. Narrowband tones from 79 to $515 \mathrm{~Hz}$, as well as broadband LFM signals, are analyzed. Conventional beamforming is applied to the narrowband arrivals. The direct path is clearly visible within $10 \mathrm{~km}$. A strong bottom bounce path, biased toward broadside, is evident for the entire duration of the transect. The bottom bounce arrivals spread in angle from $15^{\circ}$ to $30^{\circ}$. The narrowband signals are also Doppler processed followed by phone averaging. The bottom bounce arrival is visible in the Doppler-time plot, and there is an associated spread in the arrivals, indicative of either vertical scattering or out-of-plane scattering. The broadband beam-matched filter response for a close range transmission is presented showing both the direct path and the bottom bounce, spread over $2 \mathrm{~s}$ and $60^{\circ}$ around broadside. This is the most direct evidence in the paper showing the importance of out-ofplane scattering compared to in-plane vertical scattering.

To investigate the impact of a rough sea-surface and seafloor, PE modeling is performed. Three model runs are computed, and the corresponding BTR, DTR and beammatched filter responses are compared with the data. The three model runs are (a) flat sea-surface and seafloor, (b) flat surface, measured bathymetry, and (c) surface waves and measured bathymetry. The vertical scattering associated with bottom roughness, and to a lesser extent sea-surface roughness, are found to explain partially the redistribution of bottom bounce energy in bearing and in Doppler. In-plane rough boundary scattering is found, in this set of simulations, to be incapable of reproducing the beam-time impulse response measured in the data.

\section{ACKNOWLEDGMENTS}

This work was supported by the Office of Naval Research, Ocean Acoustics, under contract N00014-11-M-0170. The authors would like to acknowledge the captain and crew of both the R/V Melville and the R/V Kilo Moana. Their professionalism and skill were central to the successful completion of this experiment. Thanks to Peter Worcester for discussion and a thorough review of the manuscript.

\section{APPENDIX: BOTTOM MODEL FOR THE WESTERN PHILIPPINE SEA}

Although seafloor sediments vary significantly in thickness and sound speed over the spatial scale of the Philippine Sea acoustic experiments (Karig, 1975), it is convenient for acoustic modeling to assume a single depth-dependent 
TABLE I. A bottom model for the Western Philippine Sea.

\begin{tabular}{lccc}
\hline \hline $\begin{array}{l}\text { Depth below } \\
\text { seafloor }(\mathrm{m})\end{array}$ & $\begin{array}{c}\text { Sound } \\
\text { speed }(\mathrm{m} / \mathrm{s})\end{array}$ & $\begin{array}{c}\text { Density } \\
\left(\mathrm{kg} / \mathrm{m}^{3}\right)\end{array}$ & $\begin{array}{c}\text { Attenuation } \\
(\mathrm{dB} / \text { wavelength })\end{array}$ \\
\hline 0 & 1600 & 2000 & 0.1 \\
521 & 2100 & 2000 & 0.1 \\
521 & 5000 & 3500 & 0.1 \\
1021 & 5000 & 3500 & 1 \\
1121 & 5000 & 3500 & 10 \\
\hline \hline
\end{tabular}

bottom profile for the whole region (Table I). This model was based on results from the Deep Sea Drilling Project (DSDP) Leg 31 (Sites 290-294) (Karig et al., 1975), DSDP Leg 59 (Sites 445 to 449) (Kroenke et al., 1980), and ODP Leg 195 (Site 1201) (Salisbury et al., 2002; Salisbury et al., 2006) (Fig. 12).

Sediment thickness was based on direct drilling results. Based on previous experience in marine seismology (Goodman et al., 1989), we assumed a linear sound-speed gradient in the sediment layer from $1600 \mathrm{~m} / \mathrm{s}$ at the seafloor to $2100 \mathrm{~m} / \mathrm{s}$ at $521 \mathrm{~m}$ depth. The sediment density was based on well logging results from Site 201. At the base of the sediments, the sound speed and density change abruptly to values typical of basaltic oceanic crust. The basalt layer is much thicker than $500 \mathrm{~m}$, but for the frequencies used in the acoustic experiment $(50-400 \mathrm{~Hz})$ essentially no energy is returned from deep in the crust. Sound is attenuated by intrinsic anelasticity or scattering. The attenuation values for the sediment and upper level of the basalts are consistent with previous work in marine seismology (Sereno, 1990; Swift et al., 1998) and geoacoustics (Bowles, 1997; Udovydchenkov et al., 2012). Attenuation was allowed to

Phil Sea 2010

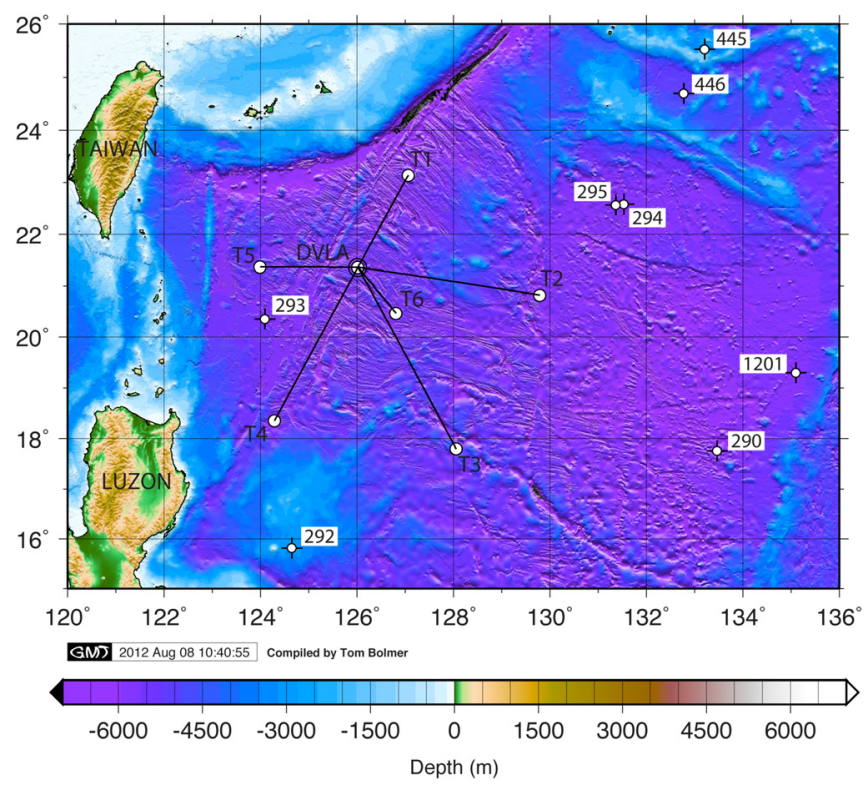

FIG. 12. (Color online) Locations of drill sites in the Western Philippine Sea along with PhilSea10 mooring locations. Sites 290-294 were drilled on DSDP Leg 31 (Karig et al., 1975); sites 445-449 were drilled on DSDP Leg 59 (Kroenke et al., 1980); and site 1201 was drilled on ODP Leg 195 (Salisbury et al., 2002). artificially increase with depth in the basalt layer to kill any energy penetrating into the basalts. The high attenuation in the bottom layer is just for absorption in the numerical code.

The sediment water interface is modeled as a discrete change in compressional speed, density, and attenuation. This leads to a reflection from the interface as well as transmission of energy into the seafloor. This approach is standard in underwater acoustic models. The quality of the model predictability of the bottom bounce in this paper demonstrates the validity of the geoacoustic model (within the frequency band of interest). A direct model-data comparison with deep vertical line array beam responses for a closing near surface source also confirmed that this model is suitable. As this is another data set, these results are beyond the scope of this paper.

Becker, K. M., Baggeroer, A. B., Heaney, K. D., Scheer, E. K., and von der Heydt, K. (2005). "ONR Five-Octave Research Array Performance During BASSEX04," in Underwater Acoustic Measurements: Technologies and Results, edited by J. S. Papadakis and L. Bjorno (Institute of Applied and Computational Mathematics, Heraklion, Crete), pp. 1249-1254.

Becker, K. M., and Preston, J. R. (2003). "The ONR Five Octave Research Array (FORA) at Penn State," in Proceedings of OCEANS 2003, Vol. 2605, pp. 2607-2610.

Bowles, F. A. (1997). "Observations on attenuation and shear-wave velocity in fine-grained, marine sediments," J. Acoust. Soc. Am. 101, 3385-3397.

Bucker, H., and Morris, H. E. (1967). "Normal-mode reverberation in channels or ducts," J. Phys. Oceanogr. 44, 827-828.

Collins, M. (1993). "A split-step Pade solution for the parabolic equation method," J. Acoust. Soc. Am. 93, 1736-1742.

Cox, H. (1996). "Fundamentals of multi-static active sonar," Report (BBN Technologies, Cambridge, MA).

Desharnais, F., and Ellis, D. D. (1997). "Data-model comparison of reverberation at three shallow-water sites," IEEE J. Ocean Eng. 22, 309-320.

Ellis, D. D., and Haller, D. R. (1987). "A scattering function for bistatic reverberation calculations," J. Acoust. Soc. Am. 82, S124.

Goodman, D., Bibee, L. D., and Dorman, L. M. (1989). "Crustal seismic structure beneath the West Philippine Sea, $17^{\circ}-18^{\circ}$ North," Mar. Geophys. Res. 11, 155-168.

Karig, D. E. (1975). "Basin genesis in the Philippine Sea," in Initial Reports of the Deep Sea Drilling Project, by D. E. Karig, J. C. Ingle, Jr., A. H. Bouma, C. H. Ellis, N. Haile, I. Koizumi, H. Y. Ling, I. MacGregor, J. C. Moore, H. Ujiie, T. Watanabe, S. M. White, and M. Yasui (U.S. Government Printing Office, Washington, D.C.), Vol. 31, pp. 857-879.

Karig, D. E., Ingle, J. C., Jr., Bouma, A. H., Ellis, C. H., Haile, N., Koizumi, I., Ling, H. Y., MacGregor, I., Moore, J. C., Ujiie, H., Watanabe, T., White, S. M., and Yasui, M. (1975). Initial Reports of the Deep Sea Drilling Project (U.S. Government Printing Office, Washington, D.C.), Vol. 31, p. 927.

Kroenke, L., Scott, R., Balshaw, K., Brassell, S., Chotin, P., Heiman, M. E., Ishii, T., Keating, B. H., Martini, E., Mattey, D. P., Rodolfo, K., Sartori, R., Theyer, F., Usher, J. L., and Zakariadze, G. (1980). Initial Reports of the Deep Sea Drilling Project (U.S. Government Printing Office, Washington, D.C.), Vol. 59, p. 820.

Salisbury, M. H., Shinohara, M., Richter, C., Araki, E., Barr, S. R., D’Antonio, M., Dean, S. M., Diekmann, B., Edwards, K. M., Fryer, P. B., Gaillot, P. J., Hammon, W. S., III, Hart, D., Januszczak, N., Komor, S. C., Kristensen, M. B., Lockwood, J. P., Mottl, M. J., Moyer, C. L., Hakahigashi, K., Savov, I. P., Su, X., Wei, K.-Y., and Yamada, T. (2002). Proceedings of the Ocean Drilling Program, Initial Reports (Ocean Drilling Program, College Station, TX), Vol. 195, p. 586.

Salisbury, M. H., Shinohara, M., Suetsugu, D., Arisaka, M., Diekmann, B., Januszcak, N., and Savov, I. P. (2006). "Leg 195 synthesis: Site 1201-A geological and geophysical section in the West Philippine Basin from the 660-km discontinuity to the mudline," in Proceedings of the Ocean Drilling Program, Scientific Results, edited by M. Shinohara, M. H. Salisbury, and C. Richter (Ocean Drilling Program, College Station, TX), pp. 1-27. 
Sereno, T. J., Jr. (1990). "Numerical modeling of water waves recorded by a subbottom seismometer in the Southwest Pacific," J. Geophys. Res. 95, 2575-2591, doi:10.1029/JB095iB03p02575.

Swift, S. A., Lizarralde, D., Hoskins, H., and Stephen, R. A. (1998). "Seismic attenuation in upper oceanic crust at Hole 504B," J. Geophys. Res. 103, 27193-27206, doi:10.1029/98JB02124.
Udovydchenkov, I. A., Stephen, R. A., Duda, T. F., Bolmer, S. T., Worcester, P. F., Dzieciuch, M. A., Mercer, J. A., Andrew, R. K., and Howe, B. M. (2012). "Bottom interacting sound at $50 \mathrm{~km}$ range in a deep ocean environment," J. Acoust. Soc. Am. 132, 2224-2231.

Urick, R. J. (1967). Principles of Underwater Sound (McGraw-Hill, New York) p. 223. 